\title{
Influence of Ertapenem Administration on the Incidence of Carbapenem-Resistant Pseudomonas aeruginosa
}

\author{
Ana Lúcia Lei Munhoz Lima, Priscila Rosalba Domingos Oliveira, Adriana P. Paula and Arnaldo Valdir Zumiotti \\ Infectious Diseases Service - Institute of Orthopedics and Traumatology, \\ Clinical Hospital of São Paulo University Medical School; São Paulo, SP, Brazil
}

IOT - Institute of Orthopedics and Traumatology (Instituto de Ortopedia e Traumatologia), Clinical Hospital, School of Medicine, São Paulo University, started the administration of ertapenem in March 2006. The Clinical Hospital is a tertiary and quaternary healthcare center and the Institute of Orthopedics and Traumatology is exclusively designed to treat highly complex cases, counting on 200 beds. That antibiotic (ertapenem) was included in the standardization of the use of antimicrobial agents intended to treat hospital-acquired infections associated to enterobacteriaceae producing ESBL (extended spectrum beta-lactamase), including cases of post-surgical or post-traumatic bone and soft tissues infections. At IOT, the Gram-negative bacillus most frequently found in that group of infections is Klebsiella pneumoniae. Although two clinical trials have not evidenced a selection of $P$. aeruginosa strains cross-resistant to other carbapenems in patients subjected to use of that antibiotic to treat severe abdominal infections [1], a fear persists that the use of ertapenem may contribute to increasing the rate of resistance to other antimicrobial agents of the same class, mainly imipenem, in the hospital environment [2].

Resistance of $P$. aeruginosa to carbapenems may occur by several mechanisms, including a reduction in the synthesis of the porines used by this class of drugs to penetrate the bacterial cell. The reduction in synthesis of porine OprD, particularly, has been described as important for such resistance [3]. In vitro, the incubation of $P$. aeruginosa strains in several media containing ertapenem could select resistance; however, the concentration used $(1 \mathrm{mg} / \mathrm{L})$ was higher than the concentration of antibiotics that remain free in the serum of patients most of the time, and lower than the MIC (minimum inhibitory concentration) of most strains of that bacterium for ertapenem (2 to $32 \mathrm{mg} /$ $\mathrm{L})$. That finding leads us to question if the phenomenon observed in vitro could have any repercussion in the hospital environment [2].

Received on 11 December 2007; revised 6 April 2008.

Address for correspondence: Dr. Ana Lucia L. M. Lima. Rua Doutor Ovídio Pires de Campos, 333, sala A311. Zip code: 05403-010. São Paulo (SP) - Brazil. Phone/Fax: (55 11) 30696900. E-mail: ccih.iot@hcnet.usp.br.

The Brazilian Journal of Infectious Diseases 2008;12(2):105-106. (C) 2008 by The Brazilian Journal of Infectious Diseases and Contexto Publishing. All rights reserved.
From March to September 2006, the consumption of ertapenem in Infection Service-IOT, in defined daily doses (DDD) was 12.6 DDD per 1,000 patients/day. To evaluate the influence of the consumption of that antimicrobial agent on the incidence of hospital-acquired infections relating to $P$. aeruginosa resistant to imipenem, we analyzed and compared the incidences of that bacterium during the period of seven months of administration of ertapenem and in the period of seven months immediately before (September 2005 to February 2006). Historically, at IOT, the susceptibility of hospital-acquired $P$. aeruginosa strains to imipenem was $63.5 \%$. After the introduction of ertapenem, we observed $90 \%$ of susceptibility to imipenem. By analyzing the data through Fisher's exact test, we found no statistically significant difference between the two periods. The results are shown in the Table 1.

Based on such data, we concluded that, in the first seven months after the introduction of ertapenem in our clinical practice, there was no increase in the incidence of infections caused by imipenem-resistant $P$. aeruginosa. These data are compatible with findings reported by other centers using such antibiotic $[4,5]$. We believe that further analysis after longer periods using ertapenem in the hospital environment will be necessary to confirm that its use is not related to selection of $P$. aeruginosa strains cross-resistant to other carbapenems.

Table 1. Comparison of susceptibility of $P$. aeruginosa strains before and after introduction of ertapenem

\begin{tabular}{lccc}
\hline & $\begin{array}{l}\text { Total strains } \\
\text { isolated from } \\
\text { P. aeruginosa }\end{array}$ & $\begin{array}{c}\text { Strains of } \\
\text { P. aeruginosa } \\
\text { resistant to } \\
\text { carbapenems } \\
\text { (susceptibility) }\end{array}$ & p \\
\hline $\begin{array}{l}\text { Period using } \\
\text { ertapenem }\end{array}$ & 10 & $9(90 \%)$ & \\
$\begin{array}{l}\text { Period before } \\
\text { using ertapenem }\end{array}$ & 11 & $7(63.5 \%)$ & 0.743 \\
\hline
\end{tabular}




\section{References}

1. DiNubile M.J., Friedland I., Chan C.Y., et al. Bowel colonization with resistant Gram-negative bacilli after antimicrobial therapy of intra-abdominal infections: observations from two randomized comparative clinical trials of ertapenem therapy. Eur J Clin Microbiol Infect Dis 2005;24:443-9.

2. Livermore D.M., Mushtaq S., Warner M. Selectivity of ertapenem for Pseudomonas aeruginosa mutants crossresistant to other carbapenems. J Antimicrob Chemother 2005;55:306-11.
3. Quale J., Bratu S., Gupta J., Landaman D. Interplay of efflux system, $\operatorname{ampC}$, and $\operatorname{OprD}$ expression in carbapenem resistance of Pseudomonas aeruginosa clinical isolates. Antimicrob Agents Chemother 2006;50:1633-41.

4. Goff D.A., Mangino J. Ertapenem: Effect on Gram-negative pathogens 7 months after formulary addition. Proceedings of the $44^{\text {th }}$ Interscience Conference on Antimicrobial Agents and Chemotherapy (ICAAC); 2004 Oct 27-Nov 2; Washington D.C., USA.

5. Goff D.A., Mangino J. Ertapenem: Effect on Gram-negative pathogens 19 months after formulary addition. Proceedings of the $45^{\text {th }}$ Interscience Conference on Antimicrobial Agents and Chemotherapy (ICAAC); 2005 Dec 16-19; Washington D.C., USA. 